\title{
Water Treatment, Preventive Measures and the Chronic Kidney Disease in the Farming Community in Sri Lanka
}

\author{
H. R. A. L. N. Ranasinghe ${ }^{1}$, L. D. M. N. Lokuge ${ }^{1}$, J. C. Edirisinghe ${ }^{1 *}$, L. Bandara ${ }^{2}$ \\ Received : 0 $7^{\text {th }}$ November, 2014 / Accepted : $12^{\text {th }}$ March, 2015
}

\begin{abstract}
Whilst being accountable for an increasing trend in mortality and morbidity, Chronic Kidney Disease of unknown aetiology (CKDu) has become a severe burden in Sri Lanka. Even though there is no sound evidence to clarify the aetiology of CKDu, it will be worthwhile to seek out the possible measures to minimize the prevalence of the disease. Hence, this study was intended to examine the impact of water treatment and preventive measures on CKDu. Data were collected from the farming community who applies agrochemicals. Both a probit and a Logit regression were carried out to check whether there is any relationship between CKDu and related variables such as consumption of treated water and adopting safety precautions. Results reveal that age, being a male, using deep wells as a source of drinking water, and long term medication increases the probability of getting the disease while, both preventive measures and water treatment significantly reduce this probability. Therefore, ensuring an adequate supply of treated water, especially for the severely affected villages is vital. Furthermore, both government and non-government institutions should work responsibly to increase the awareness of CKDu and safety precautions, in order to save the future generation.
\end{abstract}

Keywords: Chronic Kidney Disease, preventive measures, water treatment

\section{INTRODUCTION}

Chronic Kidney Disease of unknown aetiology $(\mathrm{CKDu})$ is a different form of progressive, decreased kidney function (La Isla Foundation, 2014), which has now become one of the major health crises in Sri Lanka. World Health Organization (WHO) declares that more than 15 percent of the population aged 15-70 years in the North Central and Uva provinces in Sri Lanka are affected with CKDu, while Anuradhapura district in the North Central Province is solely accountable for 22,000 deaths. However, current status proclaims that $\mathrm{CKDu}$ is now prevalent in the North Western, Eastern, Southern and Central provinces, and parts of the Northern provinces as well (Sunil, 2014).

Paddy and chena cultivations are the most prominent livelihood in these povertystricken districts, whilst many of the victims are being recorded among male farmers and agricultural labourers. Farming has been found to be strongly correlated with the prevalence of CKDu (Athuraliya et al., 2011), Athuraliya et al (2009), reports that CKDu appeared to affect young males, from low socio-economic, paddy farming communities. However, not only males, but women and children are also suffering from CKDu. In addition, over 1,100 CKDu patients are hospitalized per month in Sri Lanka and 300 deaths recorded per year. However, the death rate may be greater than this due to many of the victims die at home (Sunil, 2014). Although, these figures show an increasing trend in mortality and morbidity due to $\mathrm{CKDu}$, the aetiology remains ambiguous.

According to the literature, some researchers have argued that high fluoride content in drinking water; presence of toxins produced by cynobacteria in surface waters, particularly in the freshwater reservoirs; presence of high 
concentrations of Cadmium (Cd) in food and drinking water etc. might be some potential causes for CKDu (Jayasekara et al., 2013; Jayasumana et al., 2013). Furthermore, some studies hypothesized that usage of aluminium vessels; excessive use of agrochemicals; consumption of food items such as lotus roots; smoking tobacco, which have high $\mathrm{Cd}$ levels; nephrotoxic ingredients in widely used ayurvedic herbal medicines (Jha, 2009); excessive dehydration in the work environment of farmers; genetic predisposition and multiplicity of all or most of the above causes will also be liable for the prevalence of $\mathrm{CKDu}$ (deAlwis, 2013). In Sri Lanka, exposure to heavy metals has been given more attention in relation to $\mathrm{CKDu}$ (Chandrajith et al., 2010). Bandara et al. (2008) attributed the occurrence of CKDu to high $\mathrm{Cd}$ levels in environmental media such as reservoir sediment, soils, rice, lotus rhizomes, and fresh water fish while Illeperuma et al.(2009) to the use of poor-quality aluminium utensils for cooking purposes and storing of drinking water in North Central dry zone. It is reported that in Sri Lanka, herbal medicines and indiscriminative use of analgesics as a cause for CKDu is unlikely (Jayatilake et al., 2013).

According to Wanigasuriya (2012), provision of safe drinking water to the $\mathrm{CKDu}$ affected areas would be favourable in disease prevention, since drinking water seems to be a likely cause for the occurrence of CKDu. However, WHO has recommended several control measures to provide some relief for its victims, through regulating fertilizers and agrochemicals, and providing safe drinking water to the $\mathrm{CKDu}-$ affected areas, better health facilities and financial support, even though the root cause of $\mathrm{CKDu}$ still remains a mystery.

Nevertheless, Jayasumana et al., (2013) declares that most of the paddy farmers in North Central, North Western and Eastern Sri Lanka are heavily exposed to pesticides and fertilizers, and paying minor attention to hazardous effects on human health, while agrochemicals are being freely and irrationally used. As a result, paddy farmers become the ultimate victims of CKDu.
Due to lack of resources and restrictions in health care spending, the management of $\mathrm{CKDu}$ has been turned out to a more difficult task in developing countries (Wanigasuriya, 2012). Rice production, being the key cultivated crop in Sri Lanka and rice, being the staple food of inhabitants, this burden of CKDu will drastically affect not only the paddy farmers, but also the Sri Lankan economy.

Majority of studies have been carried out to determine the prevalence, nature and causes of CKDu in Sri Lanka (Athuraliya et al., 2011; Bandara et al., 2008, 2010; Wanigasuriya et al., 2011; Wijewickrama et al., 2011). Therefore, this study attempts to identify factors that reduce the risk of $\mathrm{CKDu}$. Consequently, it is worthwhile to examine whether adopting preventive measures which can be used to prevent contamination when applying agrochemicals and provision of treated water which ensures safety, could truly have an influence on the incidence of CKDu. Hence, this study was carried out with the aim of determining the impact of those precautions on CKDu.

\section{RESEARCH METHOD}

\section{Study Area and Data}

Anuradhapura district was selected because reported kidney patients are comparatively higher in Anuradhapura than other districts in Sri Lanka (Figure 01). The Anuradhapura district consists of 22 Divisional Secretariat (DS) divisions which encompass 694 Grama Niladhari (GN) divisions with 2584 villages. About $16.3 \%$ of the total land is cultivated under paddy (Department of Census and Statistics, 2011). In this district, $\mathrm{CKDu}$ is the leading cause of hospital mortality (Tsukamoto, 2009). Anuradhapura General Hospital, the largest hospital in the district recorded a $227 \%$ increase in discharge of patients with the end stage of CKDu (Chandrajith et al., 2010). 


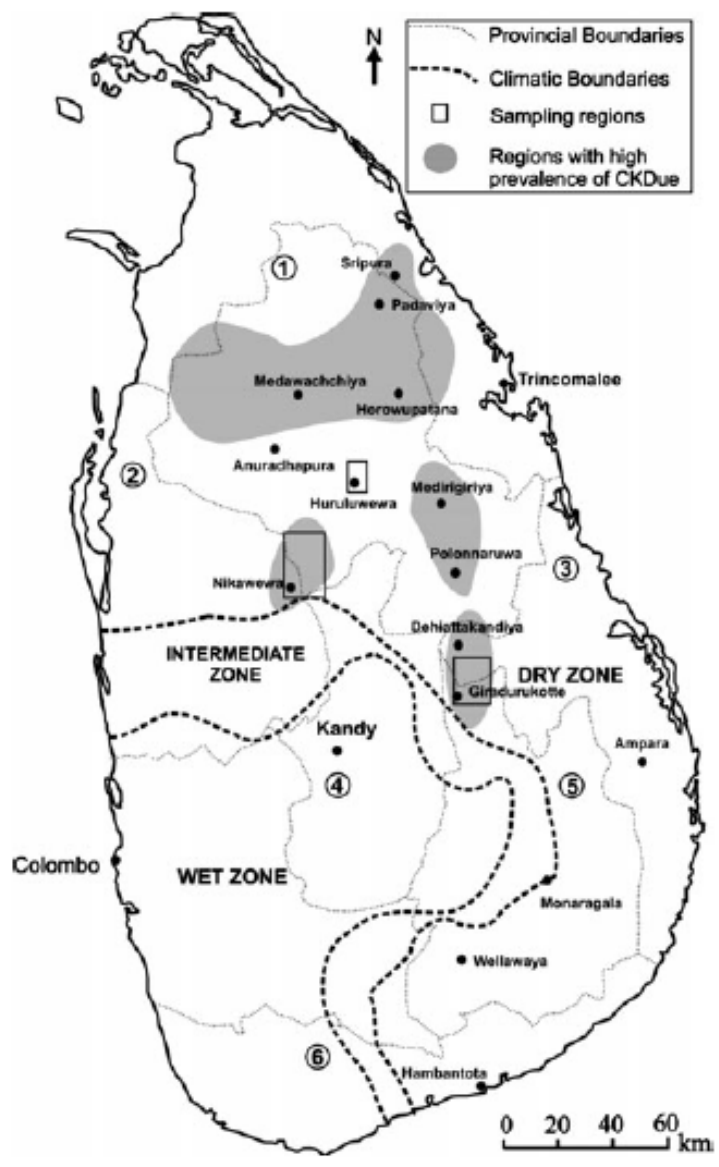

\section{Figure 01: Map showing distribution of CKDu in Sri Lanka.}

Data were collected from eight Divisional Secretariat (DS) divisions in Anuradhapura district, where CKDu can be seen more frequently. They include Padaviya, Rambewa, Galenbindunuwewa, Medawachchiya, Kebithigollewa, Manupa, Kahatagasdigiliya and Horowpathana (Table 01).175 households were randomly selected from farming communities and data were collected through face-to-face interviews, by using a well-designed pre-tested questionnaire, from March to May 2014.

\section{The Econometric Model and Data Analysis}

The nature of data on prevalence of $\mathrm{CKDu}$ is dichotomous. A respondent either reports that the $\mathrm{CKDu}$ is present or absent, that is, we observe $Y_{i}\{0,1\}$. Probit/Logit models are commonly used to analyze such dichotomous data. Assuming that an unobserved latent distribution $\left(\mathrm{Y}^{*}\right)$ is related to the presence and absence of disease $\left(\mathrm{Y}_{\mathrm{i}}\right)$, the observed variableis related to the latent as;

$Y_{i}=0$ if $Y^{*} \leq 0$

$Y_{i}=1$ if $Y^{*}>0$

Where, $\mathrm{Y}_{\mathrm{i}}=0$ if the respondent did not have $\mathrm{CKDu}$ and $\mathrm{Y}_{\mathrm{i}}=1$ if he had it. A set of covariates are related to $\mathrm{Yi}$ and as below.

$\mathrm{Y}_{\mathrm{i}}=\beta_{0}+\beta_{1} \mathrm{X}_{1}+\beta_{2} \mathrm{X}_{2}+\beta_{3} \mathrm{X}_{3}+\beta_{4} \mathrm{X}_{4}+\beta_{5} \mathrm{X}_{5}+$ $\beta_{6} X_{6}+\beta_{7} X_{7}+\beta_{8} X_{8}+\beta_{9} X_{9}+e$

Where, $\beta$ s are coefficients to be estimated and Xs are covariates. These include the variables related to water treatments, preventive measures and other control variables that may have an impact on the probability of the occurrence of CKDu (Table 02). 
Table 01: Number of patients reported at the end of 2010 .

\begin{tabular}{lc}
\hline \multicolumn{1}{c}{ Area } & Number of patients \\
\hline Anuradhapura & 1800 \\
Padaviya & 1300 \\
Sri pura & 500 \\
Medirigiriya & 600 \\
Hingurakgoda & 600 \\
Polonnaruwa & 900 \\
Giradurukotte & 2500 \\
Nickawewa & 500 \\
Medawachchiya & 2500 \\
\hline
\end{tabular}

Source: de Silva et al., (2013)

Table 02: Description of variables.

\begin{tabular}{|c|c|}
\hline Variable & Description \\
\hline X1 - Age & Measured by years \\
\hline \multirow{2}{*}{ X2 - Gender } & One dummy variable \\
\hline & male $=1$, female $=0$ \\
\hline X3- Usage of preventive measures & $\begin{array}{l}\text { One dummy variable } \\
\text { if use preventive measures }=1 \text {, otherwise }=0\end{array}$ \\
\hline X4 and X5- Source of drinking water & $\begin{array}{l}\text { Two dummy variables } \\
\text { if water source is home well }=1 \text {, otherwise }=0 \\
\text { if water source is deep well }=1 \text {, otherwise }=0 \\
\text { (piped water is considered as the reference value) }\end{array}$ \\
\hline X6-Consumption of treated water & $\begin{array}{l}\text { One dummy variable } \\
\text { if drink treated water }=1 \text {, otherwise }=0 \\
\text { (filtered and/or boiled water are considered as treated water) }\end{array}$ \\
\hline X7- Water storage & $\begin{array}{l}\text { One dummy variable } \\
\text { if water is stored in an aluminium vessel }=1 \text {, otherwise }=0\end{array}$ \\
\hline X8- Hereditaryeffect & $\begin{array}{l}\text { One dummy variable } \\
\text { if parents are } \mathrm{CKDu} \text { patients }=1 \text {,otherwise }=0\end{array}$ \\
\hline X9- Long term medication & If yes $=1$ \\
\hline
\end{tabular}

\section{RESULTS AND DISCUSSION}

\section{Description of Data}

Data include responses from 175 families involved in farming. The sample consisted of farmers with an average age around 56 years, who has been engaging in farming activities for about 27 years. The average farmer is exposed to agrochemicals approximately for 3 hours (Table 03).
Out of 175 respondents, share of females is only $8 \%$, while males account for $92 \%$. However, the sample consists of $78 \mathrm{CKDu}$ free farmers and $97 \mathrm{CKDu}$ patients. Of these CKDu patients, $97.94 \%$ are males and a mere $2.06 \%$ are females (Table 04). Athuraliya et al. (2011) and Athuraliya et al. (2009) also reported that $\mathrm{CKDu}$ is most prevalent in males. 
Table 03: Description of farmers in the sample.

\begin{tabular}{lcc}
\hline \multicolumn{1}{c}{ Variables } & Mean & Std. Dev. \\
\hline Age & 55.69 & 14.99 \\
Farming years & 27.12 & 14.13 \\
Exposing time for agrochemicals & 2.88 & 2.19 \\
\hline
\end{tabular}

Table 04: Prevalence of CKDu and gender.

\begin{tabular}{lcc}
\hline & CKDu patients & CKDu free \\
\hline \multirow{2}{*}{ Male } & 95 & 66 \\
& $(97.94 \%)$ & $(84.62 \%)$ \\
Female & 2 & 12 \\
\multirow{2}{*}{ Total } & $(2.06 \%)$ & $(15.38 \%)$ \\
\hline
\end{tabular}

Because majority of agrochemicals present a risk to the user, usually, farmers are advised to wear protective clothing when applying chemicals. Therefore, in this study, we considered wearing of protective equipment such as cap and boots, gloves, mask, and safety goggles, as preventive measures. Table 05 clearly shows that most of the farmers seldom use precautions, which have been recommended for safe use of agrochemicals. However, in comparison to other measures, wearing a mask is more popular among farmers while they seem to be unfamiliar with safety goggles yet. Moreover, it is worth noting that considerable proportion of CKDu victims (73.2\%) is the farmers who have not used any of the safeguards (Figure 02). Conversely, it also shows that, out of the farmers who use preventive measures when applying agrochemicals, $65.8 \%$ have not been affected from CKDu (Figure 03).

As depicted in the Figure 04, amid the farmers who drink water without using any type of treatment method (either filtering or boiling), notable proportion $(77.8 \%)$ has become victims of CKDu. Besides, of the farmers who treat water before drinking, comparatively a lower share $(39.8 \%)$ is $\mathrm{CKDu}$ patients, while $60.2 \%$ has been able to escape from the mystery disease.

Thus, according to these results, using safeguards when applying chemicals and drinking treated water either by boiling and/ or filtering, seems to have a negative impact on the presence of $\mathrm{CKDu}$, while disregarding them would augment the vulnerability of being a victim of CKDu.

\section{Outcome of the probit/Logit models}

Both a probit and a Logit model were estimated to verify the statistical significance of the evidence presented by descriptive statistics above. The two models were compared using Akaike Information Criteria (AIC) and Bayesian Information Criteria (BIC) and also ROC curves (Table 06 and Figure 05). There is no significant difference between the two models based on the AIC/BIC values as well as ROC curves. The areas under the ROC curves are almost similar and close to unity (0.8648 from probit and 0.8660 from the Logit). Therefore, both models fit data well. 
Table 05: Usage of preventive measures when applying agrochemicals.

\begin{tabular}{lcc}
\hline \multicolumn{1}{c}{ Precaution } & Wear & Do not wear \\
\hline Cap and boots & 11 & 164 \\
Gloves & 31 & 144 \\
Mask & 72 & 103 \\
Safety goggles & 3 & 172 \\
\hline
\end{tabular}

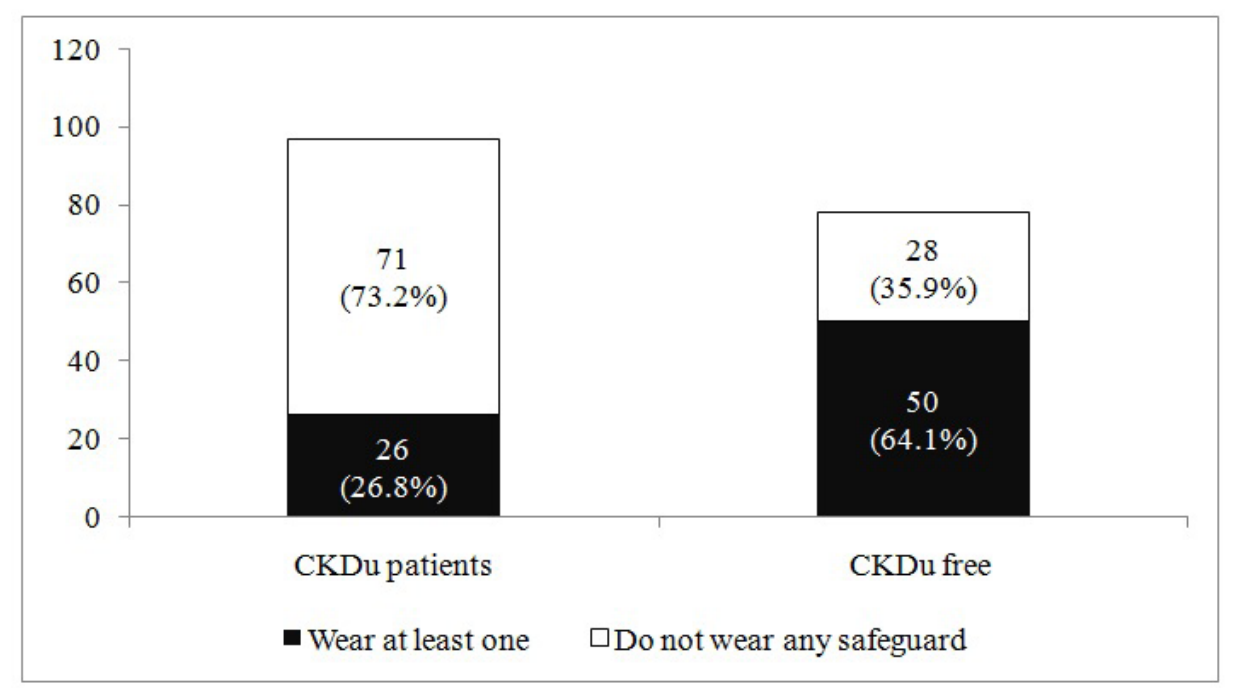

Figure 02: Prevalence of CKDu and usage of preventive measures, with respect to CKDu patients.

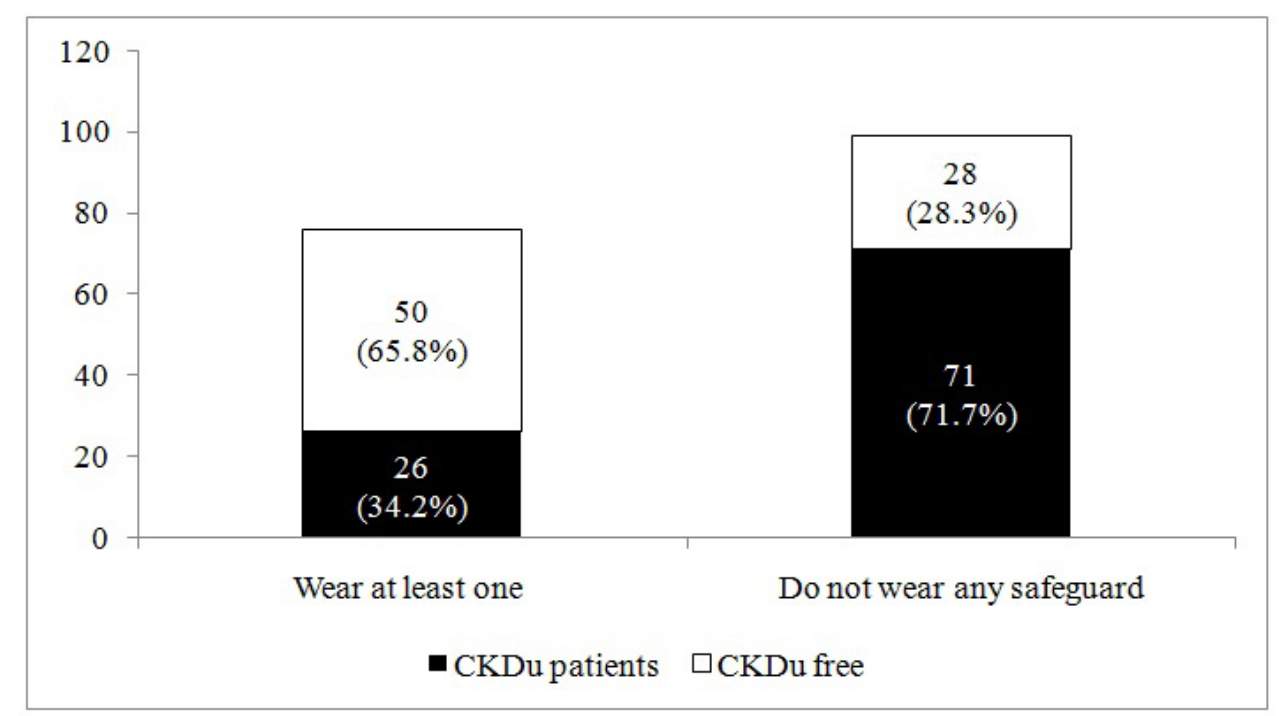

Figure 03: Prevalence of CKD and usage of preventive measures, with respect to usage of preventive measures. 


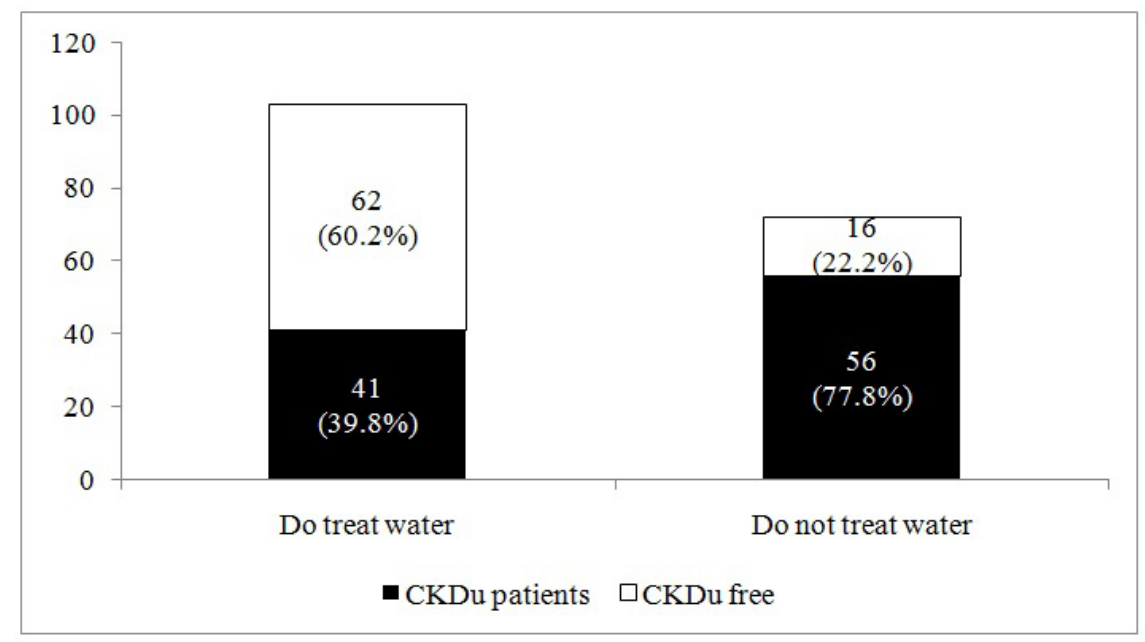

Figure 04: Prevalence of CKDu and consumption of treated water.

Table 06: Outcome of the probit and Logit models.

\begin{tabular}{|c|c|c|c|c|c|}
\hline \multirow[t]{2}{*}{ Variables } & \multicolumn{2}{|c|}{ Probit } & \multicolumn{3}{|c|}{ Logit } \\
\hline & Coefficient & $\mathrm{dy} / \mathrm{dx}$ & Coefficient & $\mathrm{dy} / \mathrm{dx}$ & Odds Ratio \\
\hline Age & $0.039 * * *$ & $0.015^{* * *}$ & $0.068 * * *$ & $0.016^{* * *}$ & $1.070 * * *$ \\
\hline Gender & $0.922 * *$ & $0.352 * * *$ & $1.501 * *$ & $0.355 * * *$ & $4.486^{* *}$ \\
\hline Usage of preventive measures & $-0.503 * *$ & $-0.195 * *$ & $-0.860 * *$ & $-0.205 * *$ & $0.423 * *$ \\
\hline Drinking water source - home well & 0.416 & 0.164 & 0.663 & 0.162 & 1.940 \\
\hline Drinking water source - deep well & $1.097 * *$ & $0.358 * * *$ & $1.859 * *$ & $0.356 * * *$ & $6.417 * *$ \\
\hline Consumption of treated water & $-0.574 * *$ & $-0.217 * *$ & $-0.932 * *$ & $-0.216^{* *}$ & $0.394 * *$ \\
\hline Store water in $\mathrm{Al}$ vessels & 0.340 & 0.126 & 0.557 & 0.126 & 1.746 \\
\hline Hereditary effect & 0.191 & 0.073 & 0.322 & 0.075 & 1.380 \\
\hline Long term medication & $1.236^{* * *}$ & $0.371 * * *$ & $2.209 * *$ & $0.376^{* * *}$ & $9.105 * *$ \\
\hline \multirow[t]{3}{*}{ Constant } & $-3.013 * * *$ & - & $-5.110 * * *$ & - & \\
\hline & \multicolumn{2}{|c|}{ AIC: 1.011} & \multicolumn{3}{|c|}{ AIC: 1.013} \\
\hline & \multicolumn{2}{|c|}{ BIC: -690.204} & \multicolumn{3}{|c|}{ BIC: -689.771} \\
\hline
\end{tabular}

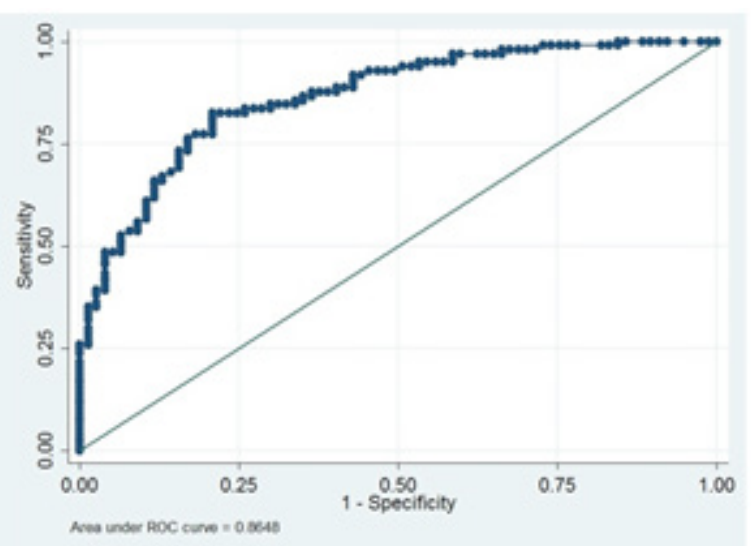

A: Probit model ROC curve

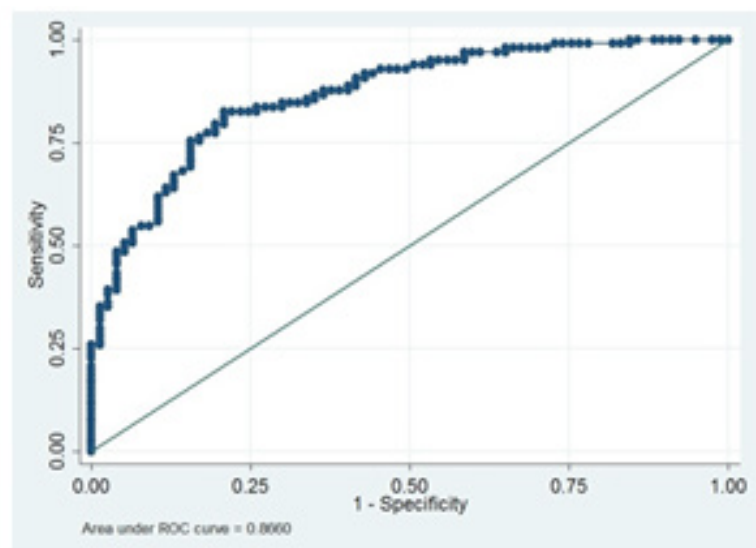

B: Logit model ROC curve

Figure 05: ROC curves from probit and Logit models. 
Of the regression estimates in Table 06, age, gender, usage of preventive measures, source of drinking water, consumption of treated water and long term medications are having a significant relationship with the prevalence of $\mathrm{CKDu}$. According to the marginal effects of regressors, it can be concluded that, the probability of occurrence of $\mathrm{CKDu}$, increases with age as has been documented as a significant risk factor previously. For example, Wanigasuriya (2012) has found a positive relationship with age and occurrence of $\mathrm{CKDu}$, while Chandrajith et al. (2010) has found that most affected age group lies between years 30-60. However, Athuraliya et al. (2009) described CKDu patients as being predominantly young males from low socio-economic farming communities. Present results also report that predominantly males are affected than females. According to Table 6 , last column, the odds of male getting CKDu is 4.486 larger than a female having $\mathrm{CKDu}$. Not surprisingly, results report that, the risk of being a CKDu victim increase, if someone uses deep wells as the source of drinking water instead of piped water. The risk is 6.42 times greater for a person using deep well as a drinking water source. It is obvious because, deep well water has a higher probability to become contaminated by metals like calcium, magnesium, strontium, iron etc., and hence, it would be detrimental for the human health. In addition, using home well as an alternative to piped lines will also enhance the danger, but not significantly as deep well water does. However, no doubt remains with the relationship which deep well and home well water hold with regard to piped water, since piped water is being transferred to villagers after going through a well-filtered process. It is reported that about $87 \%$ of the population in the Anuradhapura district use either dug well or tube well water (Perera et al., 2008). Wanigasuriya (2012) also found evidence that drinking well water in the fields increasing the risk of CKDu. Although, Bandara et al. (2008) reported high levels of Cd, iron and lead in the water in the CKDu affected areas, Chandrajith et al. (2011) reported that $\mathrm{Cd}$ content in drinking water in endemic areas are much lower. Therefore, the contaminant leading to the disease remains uncertain. However, it is interesting to note the significant negative association between prevalence of CKDu and consumption of treated water. The coefficients suggest that, if a farmer drinks water only after it is filtered and/or boiled, he could diminish the possibility of being a CKDu patient. Odds ratio shows that odd of getting the disease becomes less if respondents treat water, with compared to the respondents who donot treat water.But Sunil (2014) states that, only 40 percent of Sri Lankans have access to pipe-born water, while ground water remains as the only choice for 15 out of 25 of the country's rural districts. Under these circumstances, the results of our study emphasize the urgent need to provide proper drinking water to the rural areas of the country. Wanigasuriya(2012) correctly notes that "until the aetiology is established, provision of safe drinking water to the affected communities seems to be the only feasible option in disease prevention".

Moreover, parameter estimate for the usage of preventive measures implies that if a farmer applies agrochemicals while following safety measures, he is less vulnerable for CKDu with compared to a farmer who applies chemicals without using any type of safety measure. But unfortunately, there is a lack in awareness, skills, and expertise on various preventive measures and consequently, they are reluctant to utilize those safeguards, even though it leads them to a perilous state (Table 06). It may be because; farmers are unaware that safe application of pesticides/chemicals would prevent them from a potential terminal disease.

Both descriptive results and probit/Logit estimates comply with each other, while corroborating how prevalence of $\mathrm{CKDu}$ varies with various water treatment methods and preventive measures. Hence, facilitating the farming community with proper management practices also lies as an essential aspect to consider.

Further, hereditary effect does not show a significant effect on the prevalence of CKDu. 
Although not significant, the dummy variable which denotes the hereditary effect indicates that, when a household member is a victim of $\mathrm{CKDu}$, it arrives with an odds ratio of more than one. Wanigasuriya (2012) reported that subjects with a family member with a renal dysfunction are 4.5 times likely to have chronic renal failure. In our analysis it is 1.3 times, but is not significant. However, he noted that it is unclear to declare that this is due to hereditary effect or due to subjects being exposed to the same environmental conditions. Hence, this needs further exploration with proper medical data.

In this study, researchers have included two other variables as possible causes of CKDu as suspected by previous literature. For instance, leaching of heavy metals such as aluminium and lead, under high fluoride stress represents a new way for the entry of toxic heavy metals into the body (Illeperumaet al., 2009). Therefore, a dummy variable was included to capture any impact of aluminium vessels used for storage of water. Data fails to show significant impact of this variable. However, an odds ratio of more than one was returned. Another similar concern held in literature is the effect of long term medication as the cause of the disease. For example, Jha (2010) has suggested a link between herbal and indigenous medicines and $\mathrm{CKDu}$. To control for this fact, we included a dummy variable to represent respondents who are on long term medications. Results report that odds of a person under long term medication to have $\mathrm{CKDu}$ is about nine times higher than a person who is not.

\section{CONCLUSIONS}

By focusing on the Anuradhapura district in
Sri Lanka, this study examined the impact of preventive measures and water treatment methods on CKDu, with the aid of a probit and Logit regressions. The negative influence on the probability of occurrence of $\mathrm{CKDu}$, from using safety precautions when applying agrochemicals and drinking treated water is truly noteworthy to consider. However, availability of treated water would make more sense in preventing the possibilities of CKDu. This leads to two forms of policy implications. First is the provision of safe drinking water especially, in the endemic areas. Piped drinking water provides a solution, but may be expensive to implement given the investments necessary to supply for households scattered throughout rural areas. Therefore, local treatment at household level need to be encouraged may be in the form of subsidized availability of water treatment facilities/ equipment. Second is awareness. People in the affected areas already know the severity of the disease. However, they may not know that safe use of agrochemicals and water treatment reduces the chance of $\mathrm{CKDu}$ significantly. Therefore, extension agents in those areas have a decisive role to play in providing knowledge to farmers and encouraging them to use agrochemicals wisely with proper precautions. Nevertheless, the long term solution to this problem lies in identification of the aetiology and dealing with that because as previous research suggests, that humans can be infested with the causal agents not only from water, but through food as well.

\section{ACKNOWLEDGEMENTS}

Authors wish to extend their utmost gratitude to all respondents who gave their immense cooperation for this study.

\section{REFERENCES}

Athuraliya, T. N. C., Abeysekera, D. T. D. J., Amerasinghe, P. H., Kumarasiri, P. V. R. and Dissanayake, V. (2009). Prevalence of chronic kidney disease in two tertiary care hospitals: high proportion of cases with uncertain aetiology. Ceylon Medical Journal. 54(1): 23-25. 
Athuraliya, N. T., Abeysekera, T. D., Amerasinghe, P. H., Kumarasiri, R., Bandara, P., Karunaratne, U. and Jones, A. L. (2011). Uncertain etiologies of proteinuric-chronic kidney disease in rural Sri Lanka. Kidney International. 80(11): 1212-1221.

Bandara, J. M. R. S., Senevirathna, D. M. A. N., Dasanayake, D. M. R. S. B., Herath, V., Bandara, J. M. R. P., Abeysekara, T. and Rajapaksha, K. H. (2008). Chronic renal failure among farm families in cascade irrigation systems in Sri Lanka associated with elevated dietary cadmium levels in rice and freshwater fish (Tilapia). Environmental Geochemistry and Health. 30(5): 465-478.

Bandara, J.M., Wijewardena, H. V., Liyanege, J.,Upul, M. A. and Bandara, J. M. U. A. (2010). Chronic renal failure in Sri Lanka caused by elevated dietary cadmium: Trojanhorse of the green revolution. Toxicology Letters. 198:33-39.

Chandrajith, R., Seneviratna, S., Wickramaarachchi, K., Attanayake, T., Aturaliya, T. N. C. and Dissanayake, C. B. (2010). Natural radionuclides and trace elements in rice field soils in relation to fertilizer application: study of a chronic kidney disease area in Sri Lanka. Environmental Earth Sciences. 60(1): 193-201.

Chandrajith, R., Nanayakkara, S., Itai, K., Aturaliya, T. N. C., Dissanayake,C. B., Abeysekera, T., Harada, K., Watanabe, T. and Koizumi,A.(2011).Chronic kidney diseases of uncertain etiology (CKDue) in Sri Lanka: geographic distribution and environmental implications. Environmental Geochemistry and Health. 33:267-278.

deAlwis, K. (2013). Chronic Kidney Disease - when scientists disagree.http://nas-srilanka. org/? $\mathrm{p}=599$. 20.03.2014.

de Silva, N., Paranagama, P., Amarasinghe, M., Senanayake, K.,Dahanayake, K., Jayasumana, C. and Fonseka, S. (2013). Chronic Kidney Disease of unknown etiology (CKDu) and arsenic poisoning due to illegal pesticides.www.arsenic.lk/content/Situation_in\%20_Sri\%20Lnka/.

Department of Census and Statistics. (2011). District Statistical Hand Book Anuradhapura, Department of Census and Statistics, Colombo.

Illeperuma, O. A., Dharmagunawardhane, H. A. and Herarh, K. P. R. P. (2009). Dissolution of aluminium from substandard utensils under high fluoride stress: a possible risk factors for chronic renal failures in the North-Central Province. Journal of the National Science Foundation of Sri Lanka. 37(3): 219-222.

Jayasekara, J. M. K. B., Dissanayake, D. M., Gunaratne, M. D. N., Sivakanesan, R. and Dissanayake, D. M. T. S. (2013). Prevalence of G6PD deficiency in patients with Chronic KidneyDisease of unknown origin in North Central region of Sri Lanka: case control study. International Journal of Recent Scientific Research. 4(4): 455 - 458.

Jayasumana, M. A. C. S., Paranagama, P. A., Amarasinghe, M. D., Wijewardena, K. M. R. C., Dahanayake, K. S., Fonseka, S. I., Rajakaruna, K. D. L. M. P., Mahamithawa, A. M. P., Samarasinghe, U. D. and Senanayake, V. K. (2013). Possible link of chronic arsenic toxicity with Chronic Kidney Disease of unknown etiology in Sri Lanka. Journal of Natural Sciences Research.3(1): 64-73. 
Jayatilake, N., Mendis, S., Maheepala, P. and Mehta, F. R. (2013). Chronic kidney disease of uncertain aetiology: prevalence and causative factors in a developing country. $B M C$ Nephrology. 14(1): 1-13.

Jha, V. (2009). Current status of chronic kidney disease care in Southeast Asia. Seminars in Nephrology. 29(5):487-496.

Jha, V. (2010).Herbal medicines and chronic kidney disease. Nephrology. 15(Suppl 2): 10-17.

La Isla Foundation.(2014). What is CKD? https://aislafoundation.org/epidemic/. 12.03.2014.

Perera, A. P. G. R. L., Gonawala, J. M. L. and Wijekoon, D. (2008). Groundwater quality in Anuradhapura district with special reference to fluoride. Groundwater in SriLanka, National Academy of Science. 48-64.

Sunil, W. A. (2014). Chronic Kidney Disease spreads in rural Sri Lanka. http://www.wsws.org/en/ articles/2014/03/05/slfm-m05.html. 20.03.2014.

Tsukamoto, Y., Wang, H., Becker, G., Chen, H. C., Han, D. S., Harris, D. and Hishida, A. (2009). Report of the Asian Forum of Chronic Kidney Disease Initiative (AFCKDI) 2007. "Current status and perspective of CKD in Asia": diversity and specificity among Asian countries. Clinical and Experimental Nephrology. 13(3): 249-256.

Wanigasuriya, K. P., Peiris-John, R. J. and Wickremasinghe, R. (2011). Chronic kidney disease of unknown aetiology in Sri Lanka: is Cd a likely cause? BMC Nephrology. 12:32.

Wanigasuriya, K. (2012). Aetiological factors of Chronic Kidney Disease in the North Central Province of Sri Lanka: A review of evidence to-date. Journal of the College of Community Physicians of Sri Lanka. 17(01): 21-42.

Wijewickrama, E. S., Weerasinghe, D., Sumathipala, P. S., Horadagoda, C., Lanarolle, R. D. and Sheriff, R. M. (2011). Epidemiology of chronic kidney disease in a Sri Lankan population: experienceof a tertiary care center. Saudi Journal of Kidney Diseases and Transplantation. 22:1289-1293. 